\title{
LA UNIÓN DE PROFESORES UNIVERSITARIOS ESPAÑOLES EN EL EXILIO
}

\author{
The Union of Spanish Professors in Exile
}

\section{Jaume Claret Miranda ${ }^{\&}$}

Fecha de recepción: 20/06/2018 - Fecha de aceptación: 09/10/2018

Resumen. Tras la Guerra Civil española, miles de personas tomaron el camino del exilio, entre ellas un grupo importante de destacados profesores e investigadores universitarios. Su volumen les llevó a crear la Unión de Profesores Universitarios Españoles en el Exilio (UPUEE) con el doble objetivo de crear una red de apoyo mutuo y de presentarse como la alternativa legítima - académica y políticamente- a la universidad franquista. Con el inicio de la Segunda Guerra Mundial, su actividad se trasladó mayoritariamente a las repúblicas americanas y en otoño de 1943 se celebró en Cuba un primer Congreso para consolidar los objetivos fundacionales, en la confianza que una victoria Aliada les permitiría retornar a España y protagonizar su recuperación científica y democrática. La llamada Declaración de la Habana sería el punto álgido de su influencia; después vendría la decepción ante la continuidad y progresiva normalización de la dictadura española. La UPUEE no sobreviviría a la Guerra Fría. Este artículo analiza la historia, trayectoria y legado de esta organización.

Palabras claves: Universidad; Exilio; Ciencia; Franquismo.

Abstract. After the Spanish Civil War, thousands of people took the path of exile, including an important group of prominent professors and university researchers. Their number led them to create the Union of Spanish Professors in Exile (UPUEE) with the double objective of creating a network of mutual support and presenting itself as the legitimate alternative -academically and politically - to the Francoist university. With the beginning of the Second World War, its activity was transferred mostly to the American republics and in the Autumn of 1943 a first Congress was held in Cuba to consolidate the founding objectives, in the confidence that an Allied vic-

\footnotetext{
\& Departamento de Artes y Humanidades. Universitat Oberta de Catalunya. Avenida Tibidabo 3943. 08035 Barcelona. España. jclaretmi@uoc.edu
}

Cómo citar este artículo: Claret Miranda, Jaume. «La Unión de Profesores Universitarios Españoles en el Exilio». Historia y Memoria de la Educación 9 (2019): 295-317. 
tory would allow them to return to Spain and to lead the scientific and democratic recovery. While the so-called Declaración de la Habana represents the height of its influence, the continuity and progressive normalization of the Spanish dictatorship only brought their disappointment. The UPUEE would not survive the Cold War. This article analyzes the history, trajectory and legacy of this organization.

Keywords: University; Exile; Science; Francoism.

A finales de la Segunda Guerra Mundial y desde su exilio en los Estados Unidos, el ex catedrático de Derecho político Fernando de los Ríos Urruti denunciaba que «más del cuarenta por ciento de los profesores españoles en 1936 se hallan en el destierro». La cifra impactaba y, al margen de su exactitud, sus declaraciones tuvieron un importante eco. Se trataba de una voz autorizada, tanto por su conocimiento directo como antiguo ministro de Instrucción Pública y Bellas Artes, como por su prestigio personal y académico. No es casual que el Ministerio de Asuntos Exteriores franquista se apresurara a desmentirlo, contraponiendo las plazas cubiertas desde el final de la guerra civil española - en favor principalmente de adictos-, contabilizando como activos a quienes habían cumplido las sanciones dictadas y rebajando el impacto de la represión atribuyendo las bajas a muertes — sin determinar las causas-y jubilaciones. ${ }^{1}$

Sin embargo, la disputa evidenciaba la existencia de un importante desmoche de las plantillas docentes y, en general, de las clases más ilustradas de la sociedad española. En un ataque de sinceridad, el ministro de Educación Nacional, Pedro Sainz Rodríguez, calificaba el éxodo como «uno de los más graves problemas que la guerra civil plantea a la cultura española». ${ }^{2}$ Él mismo reconocía que el quebranto tan sólo podía compararse con «la emigración de los afrancesados a raíz de la Guerra de la Independencia». ${ }^{3}$ Más del 15 por 100 de los exiliados en Francia se

\footnotetext{
${ }^{1}$ Expediente personal de Fernando de los Ríos y Urruti, sección Gobernación, caja 55/1972, Archivo General de la Administración (AGA). Sobre el ex ministro e intelectual republicano: Virgilio Zapatero, Fernando de los Ríos. Biografía intelectual (Valencia: Pre-Textos, 2000).

${ }^{2}$ Alicia Alted, «Notas para la configuración y el análisis de la política cultural del franquismo en sus comienzos: la labor del Ministerio de Educación Nacional durante la guerra», en España bajo el franquismo, ed. Josep Fontana (Barcelona: Crítica, 2000), 223.

3 «Cultura y propaganda. Carácter y espíritu de la reforma educativa», caja 4, Archivo de Pedro Sainz Rodríguez.
} 
adscribieron a la categoría de profesionales, maestros, catedráticos, intelectuales y artistas.

Se ha calculado, por ejemplo, que en las postrimerías de la guerra civil huyeron, por la frontera catalana, dos mil médicos, mil abogados, quinientos ingenieros, siete rectores de Universidad, ciento cincuenta y seis catedráticos y doscientos treinta y cuatro escritores y periodistas. ${ }^{4}$

En el caso estricto del profesorado universitario, sabemos que, de los 600 catedráticos existentes en 1936, 193 fueron objeto de alguna sanción y, de ellos, 140 expulsados. A estos datos debemos sumar las penas menores, las condonadas o cumplidas, las penas dictadas por otras instancias represoras, la prisión y la incertidumbre. Y aún sumar los efectos de la depuración sobre el resto de profesorado no numerario. ${ }^{5}$

La magnitud de la purga facilitó que se constituyera en París el 21 de diciembre de 1939 la Unión de Profesores Universitarios Españoles en el Extranjero (UPUEE). El proyecto consolidaba los intentos que, desde agosto del mismo año, habían intentado sumar las diferentes iniciativas para agrupar a los intelectuales dispersos por la guerra civil y la derrota republicana. En un primer momento, contaron con el apoyo del Instituto de Cooperación Intelectual de París y la Society for the Protection of Science and Learning de Cambridge: los primeros facilitaron la infraestructura para las reuniones, los segundos la tramitación académica y curricular. ${ }^{6}$

Si tenemos en cuenta que en 1939 el coste de formar a un universitario se elevaba a los 45.000 dólares, podemos hacernos una idea de la pérdida cuantitativa, además de la cualitativa, que representaba la expatriación de estos docentes. Este despilfarro de capital humano se com-

\footnotetext{
${ }^{4}$ Manuel Andújar y Antonio Risco, «Crónica de la emigración en las revistas», en El exilio español de 1939, dir. José Luis Abellán (Madrid: Taurus, 1976) volumen III, 16. Dolores Pla Brugat, «El exilio republicano español», Aula-Historia Social 13 (2004): 19.

${ }^{5}$ Luis Enrique Otero Carvajal, La ciencia en España, 1814-2015. Exilios, retornos, recortes (Madrid: Libros de la Catarata, 2017), 121-128.

${ }^{6}$ José María López Sánchez, «El exilio científico republicano en México: la respuesta a la depuración», en La destrucción de la ciencia en España. Depuración universitaria en el franquismo, dir. Luis Enrique Otero Carvajal (Madrid: Universidad Complutense, 2006), 202-203.
} 
pensó, parcialmente, gracias al beneficio que obtuvieron algunos de los futuros países de acogida. ${ }^{7}$ Aunque no sin incertidumbre y dolor:

Los universitarios españoles que hemos soportado, como simples ciudadanos, las amarguras de la emigración, comunes a todos los compatriotas desterrados, hemos sufrido, además, el inmenso dolor de abandonar nuestros centros y nuestros medios de trabajo, en la mayoría de los casos sin la esperanza de recuperarlos jamás. La destrucción accidental o la destrucción premeditada, el rencor, las más bajas pasiones de venganza y hasta la incompetencia y la estupidez, han acabado con una buena parte de nuestros centros universitarios españoles, y con la casi totalidad de nuestras bibliotecas particulares. ${ }^{8}$

\section{NACE LA UPUEE}

La UPUEE tuvo como primer presidente al catedrático — de origen italiano pero nacionalizado español en 1904- Gustavo Pittaluga Fattorini (Florencia, 10-XI-1876-La Habana, 27-IV-1956). A este especialista en Parasitología y patología tropical de la Universidad de Madrid lo acompañaba, como secretario, el catedrático de Elementos de derecho natural de la Universidad de Oviedo Alfredo Mendizábal Villalba (Zaragoza, 2-IV-1897-Almería, 5-IV-1981). En este primer núcleo, también jugaron un papel protagonista el catedrático de Derecho en Salamanca Gabriel Franco López (Astorga, 14-X-1897-Madrid, 29-I-1972) y el catedrático de Filosofía del Derecho en Madrid José María Semprún Gurrea (Madrid, 1893-Roma, 1966), todos ellos firmantes de la solicitud oficial presentada ante la Prefectura de Policía de París.

Las primeras reuniones tuvieron lugar en la sede parisiense del Instituto de Cooperación Intelectual el 16 y 30 de enero de 1940. La organización seguía con expectación la evolución de la situación internacional y su posible impacto en el escenario español, así como la concreción

\footnotetext{
${ }^{7}$ Laura Fermi, Inmigrantes ilustres. La historia de la migración intelectual europea 1930-1941 (Buenos Aires: Omeba, 1971), 20.

${ }^{8}$ Ignacio Bolívar Urrutia, «Presentación», Boletín informativo (México: Sección Mexicana de la UPUEE, 1943), citado por Francisco Giral, Ciencia española en el exilio (1939-1989). El exilio de los científicos españoles (Barcelona-Madrid: Anthropos-CIERE, 1994), 22-23.
} 
de las propias oportunidades laborales y académicas. Esto último implicaba realizar una tarea de proselitismo entre todo el profesorado exiliado por parte de los ya socios y de propaganda ante las diferentes instituciones culturales extranjeras para poner en valor a sus miembros. El trabajo fue eficaz, pues en septiembre de 1940 ya contaba «con cerca de 200 miembros, cifra en torno a la cual se moverá durante toda su existencia, de los cuales 96 eran catedráticos». ${ }^{9}$

Se trataba, por lo tanto, de tejer una red básica de apoyo y ayuda mutua en tiempos convulsos y de reunir a los docentes políticamente comprometidos con la República o, al menos, con la democracia y las libertades. De hecho, durante la guerra, el mismo Pittaluga, vinculado al ex presidente Niceto Alcalá-Zamora, aunque se puso a disposición de la República, se instaló en París tras un breve paso por Madrid donde declaró: «Si he venido es para tratar de arreglar mis cosas, ahora me iré hasta que esto finalice; se han empeñado en que seamos rojos o azules y yo no puedo ser ni una cosa ni otra». ${ }^{10}$

La expansión del exilio supuso también la de la UPUEE, con delegados más o menos oficiales como el catedrático de Derecho romano de Madrid José Castillejo Duarte en Gran Bretaña, el catedrático de Química orgánica de Madrid José Giral Pereira en México, el catedrático de Derecho penal de Murcia Mariano Ruiz-Funes y el catedrático de Microbiología de Barcelona Pedro Domingo Sanjuán en Cuba, el investigador del Instituto de Investigación Animal de Madrid Pedro Couceiro Corral en Uruguay o el diplomático Alfredo Matilla Jimeno en la República Dominicana. Además, la importancia de dichas delegaciones se incrementó ante la evolución de la recién iniciada Segunda Guerra Mundial.

La incertidumbre la resolvió el avasallador avance de las tropas alemanas que provocó la huida hacia América de la mayoría de catedráticos y profesores, no sin algunas dificultades para quienes quedaron momentáneamente retenidos en la Francia ocupada. Con ellos también se desplazó la asociación y modificó su nombre, pues la última «e» pasó a ser «en el Exilio» (aunque algunos autores hablan de «emigrados» y re-

\footnotetext{
${ }^{9}$ López Sánchez, «El exilio científico republicano en México», 203-204.

${ }^{10}$ Silvestre Martín Gómez, Vida y obra de Don Gustavo Pittaluga Fattorini (Madrid: Editorial de la Universidad Complutense de Madrid, 1988), 28.
} 
trasan el cambio hasta 1943). ${ }^{11}$ Las esperanzas de un retorno rápido o, como mínimo, de un refugio próximo a España se desvanecían. El exilio era ya definitivamente real y las menguantes posibilidades de volver a casa pasaban a depender de cómo finalizase la conflagración mundial.

El doctor Pittaluga se exilió en Cuba, buscando un país poco marcado políticamente (Mendizábal se instaló en los Estados Unidos). Forzados a cruzar el Atlántico, el resto se repartió por distintas repúblicas, siendo México el destino principal. La política de puertas abiertas del presidente Lázaro Cárdenas del Río, con iniciativas como la fundación de la Casa de España el 20 de agosto de 1938, dotó de un importante peso a dicha delegación, hasta el punto que su presidente, el catedrático de Entomología de la Universidad de Madrid Ignacio Bolívar Urrutia (Madrid, 9-XI-1850-México DF, 19-XI-1944), asumiría la dirección de la UPUEE en otoño de 1943, y México se convertiría en la sede de su máximo órgano directivo, cerrándose así el paréntesis cubano. $^{12}$

Por esta mayor masa crítica, fue en la capital mexicana donde se registró la UPUEE, bajo leyes mexicanas, como asociación civil y aceptando tanto a catedráticos, auxiliares y ayudantes universitarios como a miembros de Institutos y Centros superiores de investigación. Se realizaron gestiones para lograr que los universitarios españoles residentes en otras repúblicas hispanoamericanas creasen sus propios grupos locales como delegaciones. Así, el activo grupo mexicano se reunió con representantes de todas las legaciones diplomáticas presentes en el Distrito Federal (a excepción de la argentina, cuyo gobierno mantenía una política sumamente restrictiva respecto de la acogida de nuevos inmigrantes), y contactó con todos los rectores de universidades mexicanas para conseguir trabajo a los profesores exiliados, promover ciclos de conferencias y facilitar su reconocimiento como colectivo. ${ }^{13}$

\footnotetext{
${ }^{11}$ Martín Gómez, Vida y obra de Don Gustavo Pittaluga Fattorini, 28-29. Para la tesis de «emigrados», Giral, Ciencia española en el exilio, 239: «se decidió cambiar el significado de la última E: Emigrados en lugar de Extranjero que cuadraba bien en París pero que en Hispanoamérica nos hacía aflorar cierto rubor».

12 Giral, Ciencia española en el exilio, 22.

13 José M. Cobos Bueno, Antonio Pulgarín Guerrero y Cristina Carapeto Sierra, «El Boletín Informativo de la Unión de Profesores Españoles Universitarios en el Extranjero», LLULL 27 (2004): $32-33$.
} 
Mientras estas gestiones obtenían sus primeros frutos, en España el régimen franquista se decidía finalmente a aprobar una ley para reorganizar la universidad. La Ley de Ordenación Universitaria (LOU) cerró las especulaciones sobre el futuro de la educación superior al consagrar el poder absoluto del rector, certificar la influencia de la Iglesia católica - evitando, de momento, la tentación de crear centros alternativos- y reducir la influencia de Falange a un mero carácter formal. También significó el retorno a un modelo de férreo centralismo madrileño y a un perfil bajo de las universidades de provincias, tanto por razones pragmáticas como por mediocridad o adhesión ciega. La LOU concluía la «restauración espiritual [...] abriendo brechas encendidas de luz y de fe españolas en el paisaje ensombrecido de una cultura desarraigada y neutra que había consumado el inmenso crimen de olvidarse de su progenie hispánica». ${ }^{14}$

Cuando la noticia llegó a América, el grupo mexicano de la UPUEE fue el primero en reaccionar con un comunicado de denuncia del sometimiento de la docencia al nacional-catolicismo, de la segregación de la investigación, de la consolidación de la depuración y del cierre a cualquier influencia extranjera o moderna. El comunicado finalizaba con una apelación directa al presidente Franklin D. Roosevelt y a la Carta del Atlántico. ${ }^{15}$ De nuevo, la confianza en la bondad de las fuerzas internacionales.

Dentro de esta voluntad a medio camino entre la vindicación de las propias cualidades científicas y el ofrecimiento como futuras autoridades académicas de una España liberada por los Aliados, se quiso impulsar una primera reunión de los miembros de la UPUEE ya en el exilio americano. La lectura interna entendía la convocatoria como una oportunidad para combatir la dispersión, retomar los contactos y mantener la red de complicidades. La lectura externa defendía el encuentro como una demostración de fuerza y compromiso con las instituciones republicanas ante el anhelado retorno. Tras sondear la Universidad de Puerto Rico y la Comisión de Cooperación Intelectual de la Sociedad de

\footnotetext{
${ }^{14}$ José Ibáñez Martín, Renacimiento científico en la investigación y en la docencia. Discurso pronunciado en la solemne inauguración de la Facultad de Ciencias (Valencia: Universidad de Valencia, 1944), 3.

${ }^{15}$ Cobos Bueno et al., «El Boletín Informativo de la Unión de Profesores Españoles Universitarios en el Extranjero», 35-37.
} 
Naciones, la predisposición del rector de la Universidad de la Habana, el jurista Rodolfo Méndez Peñate, y la presencia en la isla de Pittaluga decantaron la elección a favor de la capital cubana.

Su Consejo Universitario se pronunció favorablemente a acoger una reunión para «estudiar los problemas económicos, sociales, jurídicos, pedagógicos y morales de España, para incorporarla en el futuro a la reconstrucción de Europa, con arreglo a los postulados de la Carta del Atlántico». ${ }^{16} \mathrm{El}$ guiño a los Aliados volvía a ser más que evidente. La comisión organizadora estaba formada por el presidente y el secretario general de la UPUEE y seis representantes universitarios habaneros: el rector, el vicerrector y filósofo Roberto Agramonte, el profesor de Medicina Juan Kuori, los juristas Aurelio Sánchez Arango y Adriano G. Carmona, y el profesor de Ciencias Sociales Raúl Roa.

Cuba acogió a docentes españoles provenientes de las delegaciones de la organización en las diferentes repúblicas americanas, de Argentina a Puerto Rico. Además, el congreso invitó a 46 profesores, cuyo número final quedó reducido a dieciocho. A estos se sumaron otros participantes a título personal, así como los ya residentes en la isla caribeña, cuyo republicanismo era mayoritario. ${ }^{17}$ Finalizado el encuentro se adhirieron otros cuarenta docentes, algunos políticos republicanos, diferentes personalidades y un buen número de entidades, entre ellas «diecisiete universidades norteamericanas y cuatro hispano-americanas». ${ }^{18}$

\section{CONGRESO DE LA HABANA}

La reunión de la Habana se celebró entre el 23 de septiembre y el 3 de octubre de 1943 con un objetivo claro: el "proyecto de la vuelta a la patria». ${ }^{19}$ Fue, sin duda, el acto más importante organizado por la

\footnotetext{
16 «Reunión de Universitarios Españoles en la Habana», Mundo Libre. Revista mensual de política y derecho internacional II, no.21 (octubre 1943): 7.

17 Gastón Baquero, «Recuerdos sobre exiliados españoles en La Habana», Cuadernos Hispanoamericanos 473-474 (1989): 211.

18 «Reunión de Universitarios Españoles en la Habana», 9.

19 Teresa Rodríguez de Lecea, «La reunión de la "Unión de Profesores Universitarios Españoles en el Extranjero" (UPUEE). La Habana, septiembre de 1943», en Exilios filosóficos de España. Actas del VII Seminario de Historia de la Filosofía Española e Iberoamericana, coord. Antonio Heredia Serrano (Salamanca: Universidad de Salamanca, 1992), 115.
} 
UPUEE y el de mayor repercusión. Poco después de su celebración se impulsaba la publicación del Libro de la primera Reunión de profesores universitarios españoles emigrados, donde se resume la génesis, preliminares, sesiones, ponencias, homenajes y acuerdos de aquel acontecimiento. El libro, editado en Cuba en 1944 pero todavía localizable en bibliotecas y librerías de viejo, constituye la fuente principal de este apartado. $^{20}$

Durante los días anteriores al inicio del Congreso tuvieron lugar diferentes reuniones previas para concretar la organización de las sesiones. En estos encuentros preparatorios participaron el ex rector de la Universidad de Barcelona Pere Bosch Gimpera, el ya citado Cándido Bolívar Pieltáin, el catedrático de Derecho mercantil de Madrid José de Benito Mampel, el catedrático de Derecho civil de Salamanca Demófilo de Buen Lozano, los ya citados Fernando de los Ríos, Mariano Ruiz-Funes y José Giral, el catedrático de Química orgánica de Santiago e hijo del anterior Francisco Giral González, el catedrático de Derecho natural de Oviedo Alfredo Mendizábal Villalba, el presidente Pittaluga, el catedrático de Fisiología de Barcelona August Pi Suñer, el catedrático de Derecho político de Sevilla Manuel Martínez Pedroso, el catedrático de Filosofía de Barcelona Joaquim Xirau Palau y la profesora de Filosofía de Madrid María Zambrano. Todos eran personalidades brillantes de la intelectualidad, las letras y las ciencias españolas, pero también miembros destacados de la élite republicana con un extenso historial de compromiso político e institucional.

Para cubrir los gastos, el presidente Pittaluga promovió exitosamente donativos entre la comunidad cubano-española residente en la isla para cubrir los diez mil dólares de coste. ${ }^{21}$ La organización y la logística implicaron a diferentes categorías de universitarios españoles exiliados, así como a profesorado de otros niveles educativos. Todos ellos pudieron participar en el pleno a través de dos representantes ofi-

\footnotetext{
${ }^{20}$ Gustavo Pittaluga, Libro de la primera Reunión de Profesores Universitarios Españoles Emigrados (La Habana: Talleres Tipográfico La Mercantil, 1944).

${ }^{21}$ Concepción Ruiz-Funes, «La Unión de Profesores Universitarios Españoles en el Exilio. Motivos y razones», en Los refugiados españoles y la cultura mexicana. Actas de las segundas jornadas celebradas en El Colegio de México en noviembre de 1996, dir. James Valender et al., (México: Colegio de México, 1999), 39.
} 
ciales: los profesores auxiliares de Medicina y Derecho, Paulino Suárez y Félix Montiel. ${ }^{22}$

La sesión de apertura, la noche del 23, empezó con la interpretación de los himnos nacionales de todas las repúblicas americanas y de la española, en la Aula Magna, cuyas banderas también decoraban el recinto. A continuación, el profesor Pittaluga leyó un discurso en el que, tras los elogios a los anfitriones, declaraba que ante la «inminencia de la sustitución del régimen que hoy pretende gobernar a España, nuestra ambición debía ser la de estudiar y preparar, sobre la base intangible de la legitimidad republicana, una nueva estructura del Estado». Convencidos, por lo tanto, de «que el régimen del general Franco caerá», se imponía pensar en la reconstrucción y, en este sentido, se habían orientado las diferentes secciones del congreso. ${ }^{23}$ Finalmente, el secretario general Mendizábal informaba de las cuestiones logísticas.

Respecto de las secciones antes citadas, mientras a las plenarias asistían observadores, periodistas y público en general, en estas sectoriales estaban presentes diferentes docentes además de los invitados oficiales. Cada una contaba con su respectivo presidente. Así, August Pi Suñer encabezaba la de "Problemas sociales», Mariano Ruiz-Funes la de «Problemas Económicos y Jurídicos», y José Giral la de «Problemas de Educación y Cultura».

Este último, destacado académico, ex rector de la Universidad de Madrid y político (significado azañista, ministro de diferentes carteras y ex presidente del Gobierno) reivindicó la continuidad de la Universidad española a pesar de la guerra y de la dictadura. Sin embargo, consciente de representar tan solo «una parte de la España perseguida», confiaba participar positivamente en la superación de la derrota. El discurso marcaba con claridad la intención última del encuentro: presionar y ofrecerse a los Aliados, en el ámbito de la universidad y la enseñanza, de cara a una futura restauración de la democracia y las libertades en España. Se expresaba de esta manera la «voluntad de continuidad como grupo fuera de España, y en esta convicción está fundamentada la extensión y los detallados pormenores de las conclusiones» de la sesión

22 «Reunión de Universitarios Españoles en la Habana», 9.

23 «Reunión de Universitarios Españoles en la Habana», 8. 
«dedicada a la educación y a la cultura. Mucho más extensas y detalladas que las de las otras secciones». ${ }^{24}$

El rector habanero cerró la sesión con un reconocimiento explícito hacia los universitarios españoles exiliados, hacia el pueblo español sometido por la dictadura y hacia la lucha por las libertades. Para Méndez Peñate, la solidaridad de los universitarios cubanos respecto de sus colegas exiliados españoles, constituía «la ofrenda de Cuba libre a la España democrática y republicana». ${ }^{25}$

La siguiente sesión plenaria se celebró la mañana del 25 de septiembre, nuevamente en la Aula Magna, y se centró en la llamada «Declaración de la Habana». En primer lugar, el presidente de la comisión redactora, Fernando de los Ríos, dio lectura al texto propuesto. En su intervención puso el acento sobre el problema internacional, asegurando que la cultura hispánica — caracterizada por la universalización del espíritu - había sido ejemplo para creaciones contemporáneas como la Sociedad de Naciones. A continuación, se sucedieron hasta tres intervenciones relevantes para profundizar sobre el sentido de la ponencia. Primero, Bosch Gimpera se refirió a la pluralidad y a la unidad de España, afirmando que era posible la integración sin opresión y con unidad. El problema nacional fue el argumento central de Demófilo de Buen, con una reivindicación de la República en guerra, una crítica del golpista Franco auxiliado por tropas extranjeras y un anuncio de reconquista gracias al espíritu de América. Finalmente, Mariano Ruiz-Funes habló sobre el régimen actual de España y denunció la ilegalidad de los rebeldes, la tiranía impuesta, la connivencia de la Iglesia católica y la actitud de las potencias extranjeras (unas ayudando a los sublevados y otras no interviniendo): «todo es miseria, esclavitud y dolor». ${ }^{26}$

Dos días más tarde, se aprovechó el nonagésimo aniversario del nacimiento de José Martí para rendirle homenaje en la Aula Magna. Bajo

\footnotetext{
${ }^{24}$ Rodríguez de Lecea, «La reunión de la "Unión de Profesores Universitarios Españoles en el Extranjero" (UPUEE). La Habana, septiembre de 1943», 120.

25 «Reunión de Universitarios Españoles en la Habana», 9-10.

26 «Reunión de Universitarios Españoles en la Habana», 10-11. Para profundizar sobre la trayectoria en el exilio del ex rector, son especialmente útiles las monografías: Yolanda Blasco Gil y Tomás Saorín Pérez, Las universidades de Mariano Ruiz-Funes: La lucha desde el exilio por la Universidad perdida (Murcia: Edit.um, 2014) y Beatriz Gracia Arce, Trayectoria política e intelectual de Mariano Ruiz-Funes: república y exilio (Murcia: Edit.um, 2014).
} 
la presidencia de Fernando de los Ríos, también intervinieron Joaquim Xirau y María Zambrano, representando respectivamente la generación intelectual más veterana, la madura y la más joven. Todos ellos glosaron al libertador cubano, cuyos anhelos de libertad y ejemplo ético se vincularon con los ideales republicanos y la esperanza de retorno a una España democrática.

La sesión de clausura no se celebró hasta el 3 de octubre. Fue entonces cuando el secretario general dio lectura a un resumen de los trabajos realizados por las tres secciones. Por su parte, el presidente de la sesión, August Pi i Suñer fue el encargado de glosar los trabajos realizados durante el congreso. El fisiólogo catalán destacó cómo, por encima de las diferencias ideológicas, existía un compromiso compartido con los valores republicanos. Culpabilizó a los rebeldes de la guerra, de destruir «cuánto hay de más puro y excelso en el espíritu de España» y de haber facilitado la guerra mundial. El discurso finalizó con el protocolario elogio a las autoridades cubanas, la esperanza de ser escuchados por la comunidad internacional y los vivas a Cuba y a España libres. Recogía el testigo y cerraba el acto el rector habanero con unas emocionadas palabras para expresar la solidaridad cubana con el futuro e inmediato restablecimiento de la justicia y la libertad en España: «curar el dolor de España significa el devolverle la República arrebatada por el fascismo internacional». ${ }^{27}$

Posteriormente, se hicieron dos copias de la «Declaración de La Habana» firmadas por el rector habanero, el secretario de la comisión preparatoria, el cubano Carmona, y por cinco catedráticos españoles en representación de las cinco facultades de la Universidad de Madrid: Zulueta, Giral, Bolívar, Pittaluga y De los Ríos. Uno de los ejemplares se depositaba en el centro cubano, mientras el otro quedaba pendiente de archivarse en la capital española cuando se recuperase la república.

Además de las tres sesiones plenarias y de las reuniones de las secciones, también tuvieron lugar diversos actos de homenaje a los asistentes, organizados por el Círculo Nacional de Periodistas, la Gran Logia de Cuba, el Centro Asturiano, el Círculo Republicano Español, el Centro Vasco, la Casa de la Cultura y Asistencia Social, el Lyceum y Lawn

\footnotetext{
27 «Reunión de Universitarios Españoles en La Habana», 11.
} 
Tennis Club, la Institución Hispano-Cubana de Cultura, Italia Libre, el Frente Nacional Antifascista y el diario El Mundo.

\section{AUGE Y CRISIS DE LA UPUEE}

Coincidiendo con el anuncio del encuentro en la Habana, en agosto de 1943 veía la luz el primer número del Boletín Informativo impulsado por la sección mexicana de la UPUEE. La iniciativa compartía objetivos con el congreso: crear red y posicionarse de cara a la esperada victoria de los Aliados que pusiera fin a un régimen franquista con lazos evidentes con las potencias del Eje. En palabras de Francisco Giral, miembro de su secretariado:

El Boletín Informativo de la UPUEE no acogía artículos originales, sino simplemente, como indica su nombre, daba informaciones escuetas de la Universidad del Exilio. Sólo se publicó desde agosto de 1943 a noviembre de 1944. En esos 16 números se comenzó a recopilar la labor publicada por todos los universitarios científicos o humanistas en forma de libros y de artículos aparecidos en revistas internacionales de todo el mundo, agrupados por Facultades: las cinco Facultades de que constaba la Universidad española.

A este carácter recopilatorio, la publicación sumaba la inclusión de artículos e informaciones críticas respecto del régimen franquista, denuncias sobre actos de censura y usurpación sufridos en el interior de España, resúmenes del encuentro de la Habana, crónicas de las vicisitudes vividas por algunos exiliados y posicionamientos en apoyo de determinadas iniciativas o discursos públicos. ${ }^{28}$

El Boletín otorgaba presencia y visibilidad a la UPUEE, pero también permitía mantener activa la red académico-científica exiliada, dar continuidad al impulso logrado en La Habana, presentarse como ejemplo de consenso y coordinación para los emigrados y anunciarse como interlocutores de una futura España democrática ante los Alia-

\footnotetext{
${ }^{28}$ Giral, Ciencia española en el exilio, 35. Para un estudio centrado en el Boletín, véase Cobos Bueno et al., «El Boletín Informativo de la Unión de Profesores Españoles Universitarios en el Extranjero», 27-60.
} 
dos. Junto con esta publicación estrictamente ligada al profesorado exiliado, sobresalió por su calidad científica y continuidad temporal Ciencia. Revista hispanoamericana de Ciencias puras y aplicadas. Editada en México, su primer número aparecía en marzo de 1940, gracias al impulso de los exiliados llegados masivamente en verano de 1939. A lo largo de sus 35 años de vida y 29 volúmenes, esta cabecera difundió artículos científicos de recopilación, originales, avances de trabajos experimentales y noticias y comentarios sobre acontecimientos científicos mundiales. Para Francisco Giral, autor de una monografía sobre dicha publicación, Ciencia resulta «fundamental para ver los frutos de la Ciencia española en el exilio». ${ }^{29}$

Tanto el florecimiento de publicaciones como el éxito del Congreso de La Habana, reforzaron a la UPUEE como institución. Así, la nueva dirección presidida por Ignacio Bolívar organizaba el 27 de diciembre de 1943 en el Palacio de Bellas Artes de la capital mexicana un encuentro para dar a conocer a la comunidad exiliada los resultados del encuentro. La asistencia fue multitudinaria, tanto por parte de emigrados españoles como de figuras relevantes de la cultura y la política mexicanas. Se buscaba, por un lado, divulgar los trabajos realizados y, por otro, realizar un llamamiento desesperado para que el mundo no olvidase a los republicanos y postularse como ejemplo para el exilio y como alternativa para una España liberada. ${ }^{30}$

Asentada la nueva junta directiva y aprobado el traslado de la sede central a México, a partir de mayo de 1944 se retomó el esfuerzo de consolidación de las delegaciones en las repúblicas americanas y en los países europeos de reciente liberación. A principios de 1945, esta tarea se había logrado completamente e incluso la muerte de Ignacio Bolívar se había superado con el nombramiento del catedrático de Oftalmología de Madrid Manuel Márquez Rodríguez (Villaseca de la Sagra, 1872-México DF, 1962) como presidente interino de la entidad hasta la elección del ya citado Francisco Giral (Salamanca, 6-VII-1911-México DF, 31-I-2002) en mayo de 1947 (tras un breve paréntesis del ínterin

\footnotetext{
${ }^{29}$ Giral, Ciencia española en el exilio, 36-37; el capítulo 6 está dedicado en exclusiva a la revista Ciencia.

${ }^{30}$ Ruiz-Funes, «La Unión de Profesores Universitarios Españoles en el Exilio. Motivos y razones», 443-444.
} 
a cargo del catedrático de Madrid Rafael Altamira Crevea, de agosto a octubre de 1946).

En esta dinámica de alianza y refuerzo cabe situar iniciativas como el consejo técnico impulsado por la Junta Española de Liberación en enero de 1944 para preparar proyectos e informes para una futura acción de gobierno, o la Comisión de estudio de los problemas de los españoles. Esta última, impulsada por la UPUEE, conforme al mandato de la reunión de La Habana, agrupó a diversas asociaciones del exilio —bajo la presidencia del ya citado Manuel Márquez y con el pedagogo Domingo Tirado Benedí (Campillo de Aragón, 1898-México DF, 1971) como secretario - con el objetivo de acordar un anteproyecto de carta política transitoria. Entre febrero de 1944 y octubre de 1945, en vísperas de la reunión de las cortes republicanas, diferentes comisiones sectoriales estuvieron elaborando programas a aplicar en una futura España liberada. ${ }^{31}$

Entre otras, debe destacarse la comisión sectorial de enseñanza presidida, como ya sucedió en La Habana, por Joaquim Xirau y con la participación de Francisco Giral, Enrique Rioja, Rubén Landa, Luis Santullano, Antonio Ballesteros, Pedro Martín Navarro, José Peinado Altable y el antes citado secretario de la Comisión. Sus conclusiones - publicadas en este monográfico- retomaban las ya lanzadas por la UPUEE en relación con la futura articulación de la política educativa y científica. Al mismo tiempo, se aprovechaba para responder a la LOU franquista de 1943. Se trataba del último programa educativo completamente desarrollado que se elaboraría en el exilio. ${ }^{32}$

Volviendo a la UPUEE, su éxito, sin embargo, estaba a punto de transformase en crisis pues, para decepción de sus esperanzas, los Aliados no únicamente desoían las demandas para derrocar la dictadura franquista, sino que poco a poco modificaban su actitud hacia ella. De

\footnotetext{
${ }^{31}$ Tomás Saorín y Yolanda Blasco Gil, «Aproximación a la denuncia de la universidad franquista desde el exilio por Mariano Ruiz-Funes y las propuestas de política educativa republicanas», CIAN-Revista de Historia de las Universidades 17, no. 2 (2014): 242. Más actual e interesante como comparativa: Tomás Saorín Pérez y Yolanda Blasco Gil, «Universidad e Hispanidad. Tres décadas de trayectorias entrecruzadas del ministro José Ibáñez Martín y el catedrático exiliado Mariano Ruiz-Funes», Revista de Indias LXXVII, 269 (2017): 263-304.

32 Saorín Pérez y Blasco Gil, «Aproximación a la denuncia de la universidad franquista desde el exilio por Mariano Ruiz-Funes y las propuestas de política educativa republicanas», 242-243.
} 
forma creciente defendían la contemporización con el régimen español, cuyo posicionamiento también había evolucionado ante la cada vez más evidente futura derrota de las potencias del Eje. Así, el 24 de mayo de 1944 el primer ministro Winston Churchill valoraba positivamente, ante la Cámara de los Comunes, el retorno a la neutralidad por parte de España, en línea, de hecho, con las comunicaciones privadas de las autoridades norteamericanas. La UPUEE respondía públicamente a esas voces y, en el caso del líder británico, le remitía primero un cablegrama y posteriormente le dedicaba el editorial del Boletín Informativo de junio-julio de 1944. El mensaje recordaba, por un lado, que su exilio y existencia como grupo era consecuencia directa de la «incompatibilidad con el régimen tirano que dice gobernar a nuestra patria» $\mathrm{y}$, por el otro, insistía en "proclamar a los cuatro vientos que no habrá paz ni justicia en el mundo mientras tal régimen, intacto o modificado en sus apariencias, subsista en España». ${ }^{33}$

Sus palabras caían en oídos sordos, pues el pragmatismo anticomunista se imponía a los ideales democráticos. Si hasta entonces la UPUEE ya se había visto asediada por problemas logísticos y económicos -estos últimos obligaron a cerrar el Boletín Informativo en octubre-noviembre de 1944, tomando parcialmente el relevo a partir de diciembre el Boletín de la Unión de Intelectuales Españoles que sobreviviría hasta finales de 1948-, ${ }^{34}$ ahora cundía la desazón y la organización languidecería en una lenta decadencia. Al alejarse la concreción de un rápido retorno, se impusieron las necesidades más inmediatas de acomodación personal y académica a un exilio que se alargaba sin fecha de finalización. Como declaraba el ex presidente de Colombia y alto dirigente de la United Nations Relief and Rehabilitation Administration (UNRRA), Eduardo Santos, en un acto público celebrado en México por la UPUEE, más allá de lamentarse poco se podía hacer y había que aceptar la realidad:

Es un instinto de defensa animal el que empuja al franquismo a tener a los universitarios españoles alejados de su pa-

\footnotetext{
${ }^{33}$ Declaraciones recogidas en Boletín Informativo 11-12 (1944): 1.

${ }^{34}$ En la Biblioteca Virtual Miguel de Cervantes puede consultarse la colección completa de esta publicación: http://www.cervantesvirtual.com/partes/239078/boletin-de-la-union-de-intelectualesespanoles (consultado el 11-12-2017).
} 
tria. Para América, la emigración de universitarios españoles ha sido un gran beneficio, cuyos frutos estamos recogiendo ya. ¡Qué magníficos embajadores de la verdadera España!. ${ }^{35}$

Esta progresiva adaptación no significó el abandono colectivo de los ideales republicanos y/o democráticos, ni la aceptación del régimen franquista, ni la renuncia a un futuro retorno, pero sí que provocó la disgregación de las personalidades hasta entonces congregadas en torno a la UPUEE en direcciones y plataformas diferentes. Se mantuvieron los esfuerzos por preservar el espíritu republicano, pero ya estrictamente en el ámbito latinoamericano, pues la universidad española ya se veía como irrecuperable. ${ }^{36}$ Desaparecía así el «institucionismo como cultura política, quedando su recuerdo exclusivamente en el legado pedagógico, la actividad en la que se refugiaron la mayoría de ellos en el exilio». ${ }^{37}$

Aunque en 1948 se produjo un último intento de reavivar la organización y de, por ejemplo, retomar los boletines informativos interrumpidos desde 1944, volver a cobrar las cuotas de socios y recabar apoyos locales por parte de las delegaciones; nada de ello acabaría por cristalizar y las asambleas generales de la UPUEE se fueron espaciando en el tiempo. "El 9 de marzo de 1954 está fechada la última acta de una reunión». ${ }^{38}$ Paralelamente y a partir de la década de los cincuenta, el franquismo lograba romper la oficial marginación internacional y conseguía integrarse progresivamente en diferentes organismos internacionales (en la FAO en 1950, en la ICAO en 1951, en la UNESCO en 1952, en la ONU en 1955...) y firmar acuerdos bilaterales como los de 1953 con los Estados Unidos y el Vaticano.

\footnotetext{
35 Declaraciones recogidas en Boletín Informativo 15-16 (1944): 7.

36 Saorín Pérez y Blasco Gil, «Universidad e Hispanidad. Tres décadas de trayectorias entrecruzadas del ministro José Ibáñez Martín y el catedrático exiliado Mariano Ruiz-Funes», 294.

37 Jorge de Hoyos Puente, «La cultura institucionista en el exilio republicano: continuidades y fracturas", en "Otras voces, otros ámbitos»: los sujetos y su entorno. Nuevas perspectivas de la historia sociocultural, Coord. Vicent Bellver, Francesco D’Amaro, Isabel Molina y Jorge Ramos (Valencia: Asociación de Historia Contemporánea y Universidad de Valencia, 2015), 73.

38 López Sánchez, «El exilio científico republicano en México», 213-217.
} 


\section{EL LEGADO DE LA UPUEE}

La UPUEE tuvo a lo largo de su trayectoria alrededor de 200 socios, «teniendo en cuenta los fallecimientos de miembros y las incorporaciones de los exiliados en formación». ${ }^{39} \mathrm{Su}$ creación evidenció una grave y peculiar situación: la guerra civil y la posterior victoria de los insurgentes habían expulsado de España a buena parte de su inteligencia. La voluntad de purga ideológica, la represión contra todo aquel que no mostrara adhesión y la persecución política habían descabezado a la llamada generación de plata de las ciencias y las letras españolas. Sin embargo, haciendo de la necesidad virtud, académicos e investigadores emigrados crearon un órgano unitario que los representara y articulara como herederos legítimos de una tradición y unas instituciones educativas y formativas democráticas, y que los protegiera de la intemperie de un exilio incierto.

Tras las vicisitudes de la huida primero de España y después de la Europa en guerra, las repúblicas americanas les habían facilitado un inicio de normalidad vital y académica. Poco después, el favorable giro bélico para los Aliados, cuyo discurso público se comprometía a acabar con las potencias del Eje y sus partidarios, les hizo confiar en la posibilidad de un retorno a una España liberada. En este ambiente propicio, la UPUEE convocaba en otoño de 1943 su primer Congreso.

El encuentro celebrado en la isla de Cuba permitió relanzar la asociación al consolidar las diferentes delegaciones, trasladar la sede central a México, impulsar iniciativas como el Boletín Informativo y presentarse ante la comunidad emigrada y los actores internacionales como un interlocutor válido. De hecho, «la UPUEE se contemplaba a sí misma como la heredera más acabada de una tradición política liberal que había alcanzado con la Segunda República su momento culminante, pero que no era ajena a la historia de España». Y, al mismo tiempo, se consideraba como el ente más capacitado «para representar los intereses y las formas de una manera de entender la acción educativa que, además, estaba en consonancia con el sistema de valores democráticos y liberales que a nivel político se pretendía defender». ${ }^{40} \mathrm{En}$

\footnotetext{
39 Saorín Pérez y Blasco Gil, «Aproximación a la denuncia de la universidad franquista desde el exilio por Mariano Ruiz-Funes y las propuestas de política educativa republicanas», 232.

${ }^{40}$ López Sánchez, «El exilio científico republicano en México», 218.
} 
otras palabras, no sólo estaban preparados para regresar, sino que además se anunciaban como la mejor apuesta para garantizar una futura ciencia y academia sincronizadas con la modernidad y una España democrática alineada con las democracias a punto de imponerse en la Segunda Guerra Mundial.

La principal concreción de este posicionamiento fue la «Declaración de La Habana», dónde académicos e intelectuales prestigiosos pero diversos se pronunciaban «como grupo de opinión intelectual y, sobre todo, moral». ${ }^{41}$ El manifiesto inauguraba también la toma de conciencia como colectivo y, por primera vez, denunciaba el franquismo de forma ampliamente compartida por emigrados de diferentes sensibilidades. La imagen de concordia resultaba novedosa en un exilio caracterizado por la división y, de hecho, su ejemplo influyó positivamente en la reconstrucción de los órganos políticos de legitimidad republicana en México en 1945.

Finalmente, el texto recogía «las principales directrices ideológicas a seguir por ese supuestamente inminente gobierno republicano». ${ }^{42}$ No se trataba, por lo tanto, de un puro posicionamiento retórico, sino de una apuesta por un rápido retorno que lo fiaba todo a la bondad de sus propuestas, al prestigio de sus firmantes y a la buena voluntad de la comunidad internacional. Entre los miembros de la UPUEE, como entre buena parte de la España exiliada, dominaban el optimismo y la esperanza sobre «los resultados que la vida internacional de aquellos años y el curso de la guerra mundial podían tener para el futuro de España». ${ }^{43}$

La prosaica geopolítica sería cruel con dicho optimismo y esperanza, pues los Aliados no estaban dispuestos a complicarse la vida derrocando al general Franco. Aunque la UPUEE, junto con otros organismos y personalidades, intentó boicotear el prestigio y el reconocimiento internacionales de la dictadura franquista, esta no vio comprometida su continuidad y, a partir de los años cincuenta, incluso normalizó en buena medida su encaje en el mundo.

\footnotetext{
41 Rodríguez de Lecea, «La reunión de la "Unión de Profesores Universitarios Españoles en el Extranjero" (UPUEE). La Habana, septiembre de 1943», 120.

${ }^{42}$ Rodríguez de Lecea, «La reunión de la "Unión de Profesores Universitarios Españoles en el Extranjero” (UPUEE). La Habana, septiembre de 1943», 113 y 125.

43 López Sánchez, «El exilio científico republicano en México», 209.
} 
Aplazado indefinidamente el regreso y abortado por tanto su papel como interlocutor cualificado de una futura España democrática, sólo les restaba su actuación como dinamizadores y articuladores del ámbito académico y científico. Sin embargo, la diversa casuística de cada país, la progresiva integración en los centros de acogida, las distancias y el tiempo también desdibujaron esta tarea. La resiliencia franquista y la preeminencia de la cotidianeidad fueron desgastando el sentido de la UPUEE. Así la continuidad política hallaba sus vías en una militancia crecientemente más sentimental que real; mientras que la científica se articuló por otras vías como la revista Ciencia e injertándose en los países de acogida.

De alguna manera, aquella generación de plata fructificó, pues sus investigaciones y maestría hallaron discípulos, laboratorios, aulas y publicaciones en el exilio y se integraron en el gran relato de la historia de las ciencias y las letras. La merma fue, más bien, para la academia y la universidad españolas, y fue una pérdida doble ya que el quebranto de 1939 apenas se corrigió en 1975. Tan sólo dos catedráticos exiliados pudieron reintegrase a la docencia en España: Francisco Giral a la Universidad de Salamanca — aunque su cátedra pertenecía a la de Santiagoy Agustín Pérez Vitoria a la Universidad de Murcia y, sobre todo, muchos de aquellos nombres permanecieron - y permanecen- injustamente olvidados o eclipsados de los anales científicos españoles por la genealogía franquista y sus, conscientes o inconscientes, herederos. ${ }^{44}$

\section{Nota sobre el autor}

Jaume Claret Miranda es profesor agregado del Departamento de Artes y Humanidades y director del Grado de Historia, Geografía e Historia del Arte de la Universitat Oberta de Catalunya. Licenciado en Ciencias de la Comunicación (UAB, 1996) y en Humanidades (UPF, 1998) y doctorado en Historia (UPF, 2004), dedicó su tesis doctoral a la historia de las universidades españolas y a la política universitaria durante la Segunda República, la guerra civil y los primeros años del franquismo,

\footnotetext{
${ }^{44}$ Para una valoración de la gestión de la memoria republicana por parte de las universidades españolas: Jaume Claret, «Memòria de la repressió franquista a la Universitat espanyola», Entremons. UPF Journal of World History 8 (2016): 26-46.
} 
posteriormente publicada como El atroz desmoche (Crítica, 2006). Su investigación se ha centrado en la historia intelectual, cultural y política española contemporánea y, actualmente, es investigador principal del proyecto «RegioCat. Regionalismo en Cataluña bajo el régimen de Franco: discursos y prácticas», integrado en el grupo de investigación IdentiCat. Es autor de diferentes artículos, capítulos y libros en historia, entre los últimos: Breve historia de las Brigadas Internacionales (La Catarata, 2016) y Pasqual Maragall: pensamiento y acción (RBA, 2017). Miembro del consejo editorial de revistas académicas (Rubrica Contemporanea y Dictatorships \& Democracies), reseña novedades de ensayo para el diario Ara.

\section{REFERENCIAS}

Alted, Alicia. «Notas para la configuración y el análisis de la política cultural del franquismo en sus comienzos: la labor del Ministerio de Educación Nacional durante la guerra». En España bajo el franquismo, editado por Josep Fontana, 215-229. Barcelona: Crítica, 2000.

Andújar, Manuel y Antonio Risco. «Crónica de la emigración en las revistas». En El exilio español de 1939, dirigido por José Luis Abellán, volumen III, 11-150. Madrid: Taurus, 1976.

Baquero, Gastón. «Recuerdos sobre exiliados españoles en La Habana». Cuadernos Hispanoamericanos 473-474 (noviembre-diciembre de 1989): 211 220.

Blasco Gil, Yolanda y Tomás Saorín Pérez. Las universidades de Mariano Ruiz-Funes: La lucha desde el exilio por la Universidad perdida. Murcia: Edit. um, 2014.

Boletín informativo. México: Sección Mexicana de la UPUEE, 1943-1944.

Claret, Jaume. «Memòria de la repressió franquista a la Universitat espanyola». Entremons. UPF Journal of World History 8 (junio de 2016): 26-46.

Cobos Bueno, José Miguel, Manuel Pulgarín Guerrero y Cristina Carapeto Sierra. «Reunión de la Unión de Profesores Universitarios Españoles, UPUEE». Ábaco. Revista de cultura y ciencias sociales 42 (2002): 61-74.

Cobos Bueno, José Miguel, Antonio Pulgarín Guerrero y Cristina Carapeto Sierra. «El Boletín Informativo de la Unión de Profesores Españoles Universitarios en el Extranjero». LLULL 27 (2004): 27-60.

Dosil Mancilla, Francisco Javier. «La JAE peregrina». Revista de Indias LXVII, no. 239 (2007): 307-332. 
Fermi, Laura. Inmigrantes ilustres. La historia de la migración intelectual europea 1930-1941. Buenos Aires: Omeba, 1971.

Giral, Francisco. Ciencia española en el exilio (1939-1989). El exilio de los científicos españoles. Barcelona-Madrid: Anthropos-CIERE, 1994.

Gracia Arce, Beatriz. Trayectoria politica e intelectual de Mariano Ruiz-Funes: república y exilio. Murcia: Edit.um, 2014.

Hoyos Puente, Jorge De. «La cultura institucionista en el exilio republicano: continuidades y fracturas». En «Otras voces, otros ámbitos»: los sujetos y su entorno. Nuevas perspectivas de la historia sociocultural, coordinado por Vicent Bellver, Francesco D’Amaro, Isabel Molina y Jorge Ramos, 70-73. Valencia: Asociación de Historia Contemporánea y Universidad de Valencia, 2015.

Ibáñez Martín, José. Renacimiento científico en la investigación y en la docencia. Discurso pronunciado en la solemne inauguración de la Facultad de Ciencias. Valencia: Universidad de Valencia, 1944.

López Sánchez, José María. «El exilio científico republicano en México: la respuesta a la depuración». En La destrucción de la ciencia en España. Depuración universitaria en el franquismo, dirigido por Luis Enrique Otero Carvajal, 177-240. Madrid: Universidad Complutense, 2006.

Mancebo, María Fernanda. «La oposición intelectual en el exilio. La Reunión de la Habana, septiembre-octubre de 1943». En La oposición al régimen de Franco. Estado de la cuestión y metodología de la investigación, coordinado por Javier Tusell, Alicia Alted y Abdón Mateos, tomo II, 57-70. Madrid: UNED, 1990.

Martín Gómez, Silvestre. Vida y obra de Don Gustavo Pittaluga Fattorini. Madrid: Editorial de la Universidad Complutense de Madrid, 1988.

Otero Carvajal, Luis Enrique. La ciencia en España, 1814-2015. Exilios, retornos, recortes. Madrid: Libros de la Catarata, 2017.

Pittaluga, Gustavo. Libro de la primera Reunión de Profesores Universitarios Españoles Emigrados. La Habana: Talleres Tipográfico La Mercantil, 1944.

Pla Brugat, Dolores. «El exilio republicano español». Aula-Historia Social 13 (primavera 2004): 14-34.

«Reunión de Universitarios Españoles en la Habana». Mundo Libre. Revista mensual de politica y derecho internacional tomo II, no. 21 (octubre 1943): 7-15.

Rodríguez de Lecea, Teresa. "La reunión de la "Unión de Profesores Universitarios Españoles en el Extranjero” (UPUEE). La Habana, septiembre de 1943». En Exilios filosóficos de España. Actas del VII Seminario de Historia de la Filosofía Española e Iberoamericana, coordinado por Antonio Heredia Serrano, 113-125. Salamanca: Universidad de Salamanca, 1992. 
Ruiz-Funes, Teresa Concepción. «La Unión de Profesores Universitarios Españoles en el Exilio. Motivos y razones». En Los refugiados españoles y la cultura mexicana. Actas de las segundas jornadas celebradas en El Colegio de México en noviembre de 1996, dirigido por James Valender et al., 435-449. México: Colegio de México, 1999.

Saorín Pérez, Tomás y Yolanda Blasco Gil. «Aproximación a la denuncia de la universidad franquista desde el exilio por Mariano Ruiz-Funes y las propuestas de política educativa republicanas». CIAN-Revista de Historia de las Universidades 17, n. ${ }^{\circ} 2$ (2014): 223-249.

Saorín Pérez, Tomás y Yolanda Blasco Gil. «Universidad e Hispanidad. Tres décadas de trayectorias entrecruzadas del ministro José Ibáñez Martín y el catedrático exiliado Mariano Ruiz-Funes». Revista de Indias LXXVII, no. 269 (2017): 263-304.

Zapatero, Virgilio. Fernando de los Ríos. Biografía intelectual. Valencia: Pre-Textos, 2000. 